\title{
Expansão do ensino de enfermagem no Brasil: evidências históricas e perspectivas da prática
}

Recebido em: 28/08/2012

Aprovado em: 25/11/2014
Simone da Silveira Magalhães Ana Maria Maia Rodrigues

Maria das Graças da Silva Guerreiro ${ }^{1}$ Maria Veraci Oliveira Queiroz ${ }^{2}$ Lucilane Maria Sales da Silva ${ }^{2}$ Consuelo Helena Aires de Freitas ${ }^{2}$

Resumo: O estudo objetivou descrever a expansão dos cursos de graduação em enfermagem e sua relevância na prática. As informações são de dados estatísticos oficiais, fornecidos pelo INEP. Estudo documental, descritivo, na abordagem quantitativa. A coleta e análise dos dados ocorreram em outubro e novembro de 2011 e sintetizam-se nos resultados: aumento do número de cursos de graduação em enfermagem a partir da LDB, especialmente na região sudeste, e o descompasso entre a oferta de vagas e o número de egressos. Considera-se que momentos histórico-sociais e políticos favoreceram o crescimento da profissão e a organização da categoria.

Descritores: Enfermagem, Educação em Enfermagem

\section{Expansion of nursing education in brazil: historical evidence and perspectives of practice}

Abstract: Aimed to understand the experiences of mothers during the breastfeeding situation in prison. Descriptive exploratory study conducted with a qualitative approach in Female Criminal Institute of Ceará. Data collection occurred in September of 2009 through semistructured individual interviews. Data analysis was performed according to content analysis. Nursing actions in this specific context is paramount, in order to promote the overall health of mother and child, while respecting the specific situation that exposes them to prison

Descriptors: Nursing, Nursing Education

\section{Expansión de la educación de enfermería en brasil: evidencias históricas y perspectivas de la práctica}

Resumen: El objetivo del estudio fue describir la expansión de los programas de postgrado en enfermería y su importancia en el Sistema Único de Información de Salud. Las estadísticas oficiales proporcionadas por el INEP. Estudio documental, el enfoque cuantitativo descriptivo. La recopilación y el análisis se llevó a cabo en octubre y noviembre de 2011 y resume los resultados: el aumento del número de cursos de pregrado en enfermería de la LDB, sobre todo en el sureste, y la falta de correspondencia entre las vacantes y el número de graduados. Se considera que los momentos socio-históricos y políticos favorecieron el crecimiento de la profesión y la organización categoria.

Descriptores: Enfermería, Educación en Enfermaria

\section{INTRODUÇÃO}

A história da Enfermagem no Brasil teve início com a colonização do País e a vinda da família real. Antes era realizada de forma bem empírica e domiciliar, e depois com as epidemias infecciosas trazidas com a chegada dos europeus. Com foco no sanitarismo campanhista, a profissão foi marcada pelo treino para combater epidemias. Nesta época, surgiu a primeira escola de enfermagem no Brasil - Escola de Enfermeiros e Enfermeiras - aliada ao Hospital de Alienados. Posteriormente, em 1923, foi criada a primeira escola sistematizada de Enfermagem, Escola de Enfermagem Anna Nery. Apesar do ensino ter sido institucionalizado em 1923, sua consolidação se efetiva somente em 1949, com a Lei no 775, como resultado de pressões profissionais por intermédio da Associação Brasileira de Enfermeiras Diplomadas ${ }^{(1)}$.

Em 1930, evidencia-se o início da necessidade de uma força de trabalho qualificada e com saúde. A reorganização econômicopolítica foi o marco para a evolução dos cursos de Enfermagem moderna no país, desenvolvimento acionado na década de 1940, com a aceleração da substituição das importações e o fortalecimento da industrialização. O ensino de Enfermagem começou a ser consolidado com o desenvolvimento industrial e a modernização dos hospitais. Assim a institucionalização do ensino de Enfermagem no Brasil estava contida num contexto que confere amplas dimensões quando remetida aos problemas de organização e funcionamento da Sociedade e do Estado(2).

Em 1972, o Plano Decenal de Saúde para as Américas definiu como uma de suas metas o aumento do quantitativo de enfermeiros, com necessidade de ampliação do quantitativo de vagas e a abertura de mais escolas de Enfermagem. Com isso, o Departamento de Assuntos Universitários (DAU/MEC) designou um grupo de enfermeiras, que integravam o Grupo Setorial de Saúde desse Departamento, para prestar assessoramento no diagnóstico sobre os cursos de Enfermagem no Brasil ${ }^{(3)}$.

Em 1974, a economia no País exibia sinais decorrentes da crise econômica do capitalismo mundial. Nas décadas seguintes, ocorreu um grande incentivo à iniciativa privada para o ensino superior, como: o CREDUC (Programa de Crédito Educativo para Nível Superior) em 1976; a crise econômica vivenciada na década de 1980; a manutenção na Constituição Federal do princípio segundo o qual "o ensino é livre à iniciativa privada"; a Lei de Diretrizes e Bases de 1996 (LDB); o Fundo de Financiamento

'Enfermeira. Aluna do Mestrado em Cuidados Clínicos em Saúde e Enfermagem na Universidade Estadual do Ceará (UECE). Email: sisimagalhaes@yahoo.com.br ${ }^{2}$ Enfermeira. Doutora em Enfermagem. Professora Adjunta do Curso de Enfermagem e do Programa de Pós-Graduação Cuidados Clínicos em Saúde e Enfermagem da UECE. 
ao Estudante de Ensino Superior (FIES) que substituiu o extinto CREDUC, há pouco citado, em 1995, que se baseia na mesma lógica do seu antecessor: o financiamento estudantil, por parte do Governo Federal, nas instituições superiores privadas e o Plano Nacional de Educação, com diretrizes e metas para os dez anos seguintes, lançado em $2001^{(3)}$.

Houve privilégio do setor privado, reforçando a ideia de que a política de expansão do ensino superior no País ocorre, preferencialmente, por via da ampliação das vagas nas instituições privadas, tendo esse reflexo em nossos dias no Programa Universidade para Todos (PROUNI), criado em 2005, que regulamenta a "compra" das vagas ociosas nas instituições privadas, destinando, desta forma, verba pública para o setor, e ainda isenção de um conjunto de impostos ${ }^{(4)}$.

Ressalta-se que a política neoliberal concretizada durante o governo do presidente Fernando Henrique Cardoso trouxe profundas mudanças na educação, uma vez que a reforma educacional retirou a educação da esfera dos chamados direitos da cidadania e a situou como um serviço disponível no mercado. As universidades públicas receberam forte impacto vendo o seu sucateamento com os cortes de verbas, não abertura de concursos públicos para professores e funcionários técnico-administrativos, continuidade da expansão do ensino superior privado, destinação de verba pública para as faculdades particulares e ausência de uma política efetiva de assistência estudantil(4).

Assim, a história política brasileira contribuiu de forma decisiva para o desenvolvimento do ensino da Enfermagem. Observa-se um crescimento significativo no número de escolas da especialidade. Pelo Decreto 5.773, de $2006^{(5)}$, que trata das funções de regulação, supervisão e avaliação de instituições de educação superior e cursos superiores de graduação e sequenciais no sistema federal de ensino.

Em 2014 o Brasil possui em torno de 734 cursos de graduação presenciais no País, graduando cerca de 39.994 pessoas por ano ${ }^{(6)}$. A expansão dos cursos de Enfermagem foi e é necessária para que haja cobertura das áreas de um país continental como o Brasil. É preciso, no entanto, que exista a qualidade do ensino para o rigor científico.

Ante tais considerações, propusemos esta reflexão pautada em questionamentos que envolvem a necessidade das instituições formadoras direcionarem seu foco nas características do ensino em saúde e, assim, assumirem com muita responsabilidade e competência a formação do enfermeiro com o pensamento de que o futuro profissional apreenda o compromisso com a saúde da população, em vez de intencionar apenas produzir números cada vez maiores de egressos. O desafio da consolidação de princípios, como o da integralidade, o compromisso e a responsabilidade do próprio SUS com a formação de seus recursos humanos, em parceria com o Ministério da Educação (MEC) e as instituições de ensino superior, nos levaram à reflexão sobre o tema, no intuito de descrever, com suporte em dados estatísticos oficiais, a expansão dos cursos de graduação em Enfermagem e as perspectivas da assistência na prática.

\section{METODOLOGIA}

Trata-se de estudo documental e descritivo com abordagem quantitativa. Os estudos descritivos são caracterizados por conterem informações, dados, inventários de elementos constitutivos ou contíguos ao objeto(7). A natureza quantitativa usa o método positivista tradicional que utiliza evidências empíricas reunidas como dados que têm raízes na realidade objetiva e são agrupados direta ou indiretamente por meio dos sentidos e não de crenças ou palpites pessoais ${ }^{(8)}$.

O estudo foi realizado utilizando como base os dados fornecidos pelo Instituto Nacional de Estudos e Pesquisas Educacionais Anísio Teixeira (INEP) ${ }^{(9)}$, coletado por meio de cadastro feito no sítio da Instituição, momento em que são produzidas informações sobre o estudo, bem como seus objetivos. Além da necessidade de aquisição de tais dados para estudos e discussão, foi solicitada a autorização para seu emprego na pesquisa.

Anualmente, o INEP realiza a coleta de dados sobre a educação superior com o objetivo de oferecer informações detalhadas acerca da situação atual e as grandes tendências do setor. A coleta dos dados esta descrito no Decreto n ${ }^{\circ} 6.425$, de 4 de abril de 2008. O censo da educação superior reúne informações sobre as instituições de ensino superior, seus cursos de graduação presencial ou a distância, cursos sequenciais, vagas oferecidas, inscrições, matrículas, admitidos e concluintes, além de informações sobre docentes, nas variadas formas de organização acadêmica e categoria administrativa ${ }^{(2)}$.

Posteriormente, após realização de cadastro e solicitação, por meio eletrônico, das informações pertinentes, os dados foram enviados para o endereço eletrônico do pesquisador solicitante. Faz-se necessário ressaltar que, consoante informações do próprio Instituto, os dados, antes de serem divulgados, são validados estatisticamente, sendo informações oficiais. A coleta e análise dos indicadores ocorreram nos meses de outubro e novembro de 2011. Os resultados foram sistematizados e mostrados em gráficos, os quais foram discutidos e fundamentados cientificamente.

\section{APRESENTAÇÃO DOS RESULTADOS E DISCUSSÕES}

Os resultados reúnem dados sobre a evolução dos cursos de Enfermagem no Brasil, ofertas de vagas e sua relação com egressos bem como a evolução periódica do número de cursos de graduação em Enfermagem no Brasil, conforme regiões geográficas, demonstrados estatisticamente nos gráficos a seguir.

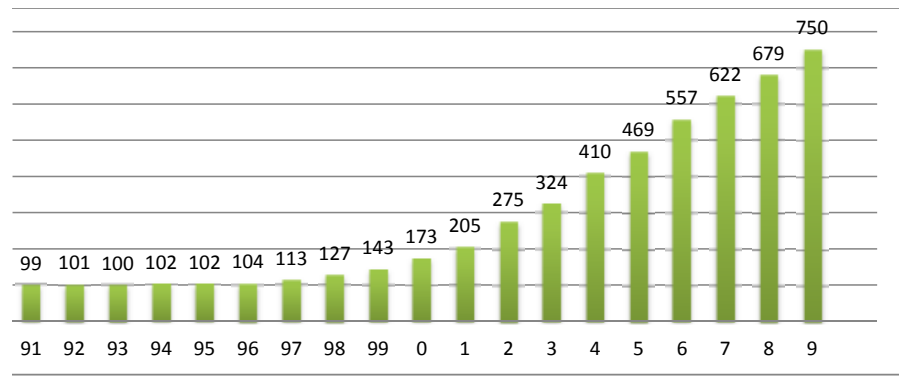

Gráfico 1: Evolução do número de cursos presenciais de graduação em Enfermagem no Brasil, entre 1991 e 2009 (Fonte: INEP).

Observa-se neste gráfico que, no Brasil, até 1996, havia pequena variação nos totais de cursos de enfermagem. Entre 1997 e 2009, percebe-se que ocorreu um aumento significativo dos referidos cursos. Associando este acontecimento ao cenário político brasileiro, lembra-se que, em 1995, Fernando Henrique Cardoso assume a Presidência do Brasil, tendo sido reeleito até 2002. No seu primeiro mandato, na educação, o foco foi na Lei de Diretrizes e Bases de 1996, que expandiu o ensino superior privado.

Entre as recomendações desta legislação tem-se: conferir 
maior autonomia às instituições de ensino superior na definição dos currículos de seus cursos, mediante a organização de um modelo pedagógico adaptado as demandas da sociedade, em que a graduação passa a se constituir etapa de formação inicial na educação contínua; e propor uma carga horária mínima que permita a flexibilização do tempo de duração do curso, de acordo com a disponibilidade e esforço do aluno.

A autonomia universitária a que se refere a LDB, ao ser aplicada segundo o entendimento dos "empresários da educação", representa liberalidade total para a criação de cursos e formatação dos "tradicionais", uma vez que os critérios estabelecidos para a aprovação de cursos são deveras facilitadores. Assim, houve um crescimento maior do total de vagas ofertadas para os cursos presenciais de graduação em Enfermagem desde o ano de 2000, que triplicou até 2009.

Relevante refletir sobre os cursos, seus projetos pedagógicos e suas interfaces com as Diretrizes Curriculares para o Curso de Enfermagem, instituídas em 2001, no que se refere a direcionar o ensino para o novo sistema de saúde. Afinal, há necessidade de enfermeiros que ocupem todo o espaço nacional, mas também existe a preocupação de se formar profissionais com características específicas e fundamentais para atuar na saúde doença nos diversos lugares do País, sendo importante primar pelo envolvimento destes cursos com as políticas de saúde, legitimando sua prática junto aos interesses da sociedade.

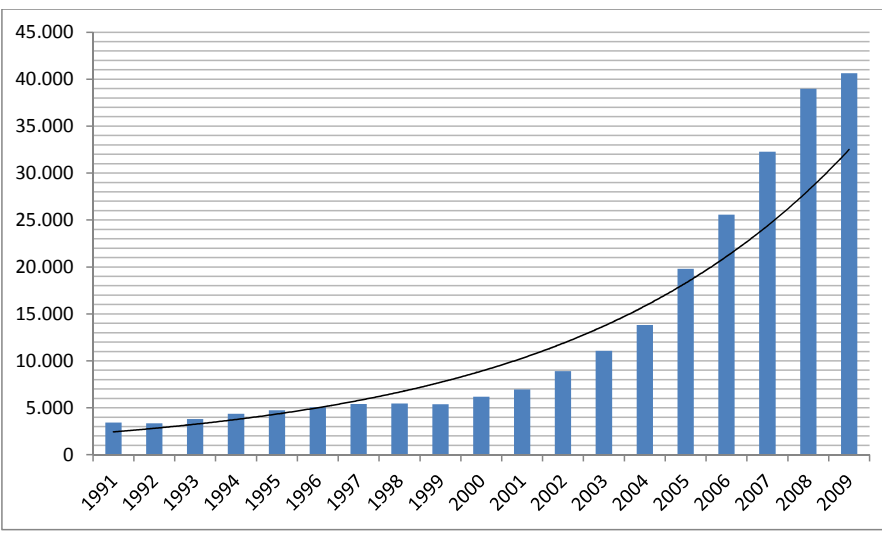

Gráfico 2: Evolução no número de egressos dos cursos presenciais de graduação em Enfermagem no Brasil, de 1991 a 2009(Fonte: INEP).

Apesar do grande crescimento no total de egressos dos cursos presenciais de graduação em Enfermagem, este não acompanhou na mesma proporção o quantitativo de vagas ofertadas para os cursos. Em 1991, foram ofertados 7.460 vagas, que ensejaram 3.434 egressos. Até meados de 1997, cerca de $50 \%$ dos profissionais que iniciavam o curso de Enfermagem o concluíam. Logo após a criação da LDB, esse aproveitamento das vagas até a conclusão do curso foi de $31 \%$ em 2000 e de $34 \%$ em 2009. Tal ocorrência conduz à reflexão sobre o ensino ou a respeito do perfil do aluno dessas escolas que surgiram, já que as vagas ofertadas aumentaram e os profissionais graduados não cresceram em igual proporção. Será que há relação com as novas diretrizes do ensino superior? Será que há vinculação com a qualidade das escolas particulares que surgiram? Ou isto diz respeito ao novo perfil do graduando em Enfermagem que agora estuda e trabalha ao mesmo tempo? Percebe-se que os dados em registro suscitam muitos questionamentos no que concerne à formação dos enfermeiros e instigam mais investigações.

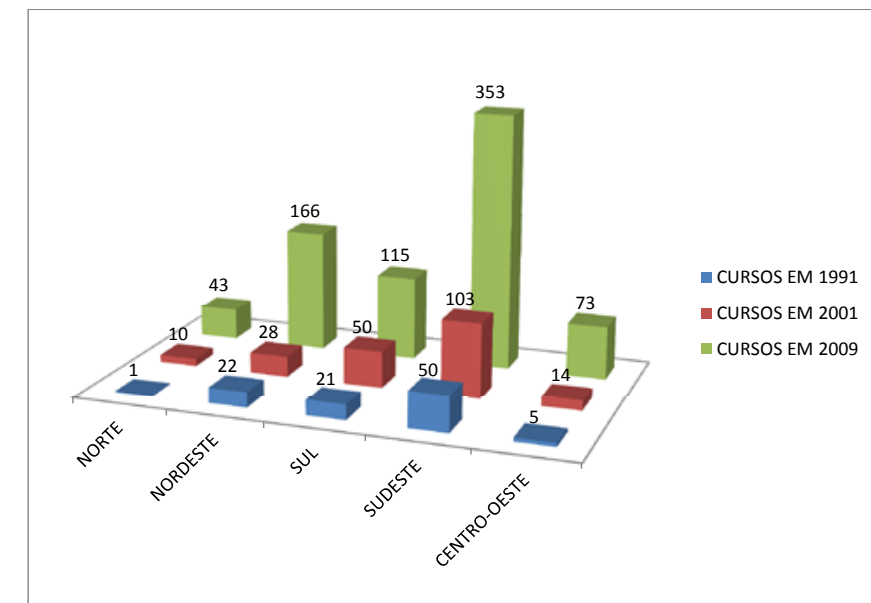

Gráfico 3: Evolução do número de cursos presenciais de graduação em Enfermagem no Brasil, conforme regiões geográficas, em 1991, 2001 e 2009(Fonte: INEP).

O gráfico 3 mostra o aumento dos cursos presenciais de graduação em Enfermagem em todas as regiões, mas, de modo mais expressivo, na região Sudeste, a mais desenvolvida do País. Isso reforça a concentração de profissionais nos maiores centros urbanos, em comparação ao défice de mão de obra qualificada nas regiões menos desenvolvidas do Brasil. Não existe, no entanto, uma garantia de que estes novos profissionais formados pelas escolas que surgiram no País respondam à demanda das localidades em défice de pessoal.

O crescimento de cursos/vagas merece um efetivo sistema de regulação por parte do Estado, no que se refere às condições de ensino, ou seja, infra-estrutura, política de recursos humanos e organização didático-pedagógica, tanto na rede pública como no sistema privado de ensino. Considerando o agravamento das condições de vida da população brasileira, seu empobrecimento, e dado que a democratização de acesso ao ensino superior aconteceu às custas do sistema privado de ensino, será possível supor que, para se manterem nos cursos, os estudantes necessitarão, cada vez mais, trabalhar para se sustentar durante a formação ${ }^{(3)}$. Acreditamos que sejam necessárias políticas educacionais e de saúde que promovam essa interiorização do ensino e suas atividades profissionais.

\section{CONSIDERAÇÕES FINAIS}

A expansão dos cursos de Enfermagem no Brasil é fomentada por questões políticas e da gestão, desde seu surgimento. Outrora, com o objetivo de conter epidemias e, atualmente, com vistas a dar cobertura assistencial a todo o País, em um momento que se vivenciam perspectivas de acesso universal à saúde com integralidade do cuidado. Estes procedimentos foram sendo fomentados por momentos histórico-sociais, articulados aos interesses políticos, favorecendo o crescimento da profissão em quantidade e em importância social e fortalecendo a organização da categoria.

Os dados expressos mostram, objetivamente, o aumento progressivo dos cursos, vagas e egressos de Enfermagem com predominância deste aumento na região Sudeste, ratificando uma predominância da profissão nos grandes centros urbanos. Enfatizamos a ideia de que a expansão do número de cursos superiores de Enfermagem é hoje uma realidade e esse dado nos leva a refletir a respeito de alguns fatores, como: necessidades de saúde da população, relação enfermeiro por habitante, 
quantitativo atingido e atendimento das necessidades de sustentação do modelo de atenção à saúde vigente no País. A simples ampliação do número de vagas e cursos não basta à sociedade, pois cremos ser importante que a profissão desenvolva o seu papel social e tenha força política para reduzir a precarização do mundo do trabalho, realidade tão comum na Enfermagem.
As condições de ensino, sua infraestrutura, a política de recursos humanos e a organização didático-pedagógica são alguns dos pontos a serem considerados para o avanço da profissão. Assim, deve-se investir na qualidade dessa formação e no compromisso desses novos trabalhadores em efetivar o resultado de tantas lutas em um sistema de saúde mais justo e igualitário, para que haja melhoria nos determinantes sociais e na qualidade da assistência à saúde no Brasil.

\section{Referências}

1. Geovanini T, Moreira A, Dornelles S, Machado WCA. História da enfermagem:versões e interpretações. Rio de Janeiro: Revinter: 2010.

2. Teixeira E, Vale EG, Fernandes JD,SordiMRLD.Trajetória e tendências dos Cursos de Enfermagem no Brasil. Rev Bras Enferm. 2006 jul-ago; 59(4): 479-87.

3. Barbosa TSC, BaptistaS de S.Movimento de expansão dos cursos superiores de enfermagem na região centro-oeste do Brasil: uma perspectiva histórica.Rev. Eletr. Enf. 2008; 10(4): 945-56.

4. Figueiredo ESA. Reforma do ensino superior no Brasil: um olhar a partir da história. Revista da UFG. 2005; AnoVII (2): Dez.

5. Brasil. Presidência da República. [on line] Decreto n 5.773 , de 9 de maio de 2006. Dispões sobre o exercício das funções de regulação, supervisão e avaliação de instituição de ensino superior e nas superiores de graduação e sequenciais no sistema federal de ensino.
6. INEP. Instituto Nacional de Estudos e Pesquisas Educacionais. Site oficial. [online] [capturado em: 11 de novembro de 2011] Disponível em: http://portal.inep.gov.br/superior-censosuperior.

7. Rodrigues RM. Pesquisa acadêmica: como facilitar o processo de preparação de suas etapas. São Paulo: Atlas: 2007.

8. Polit DF, Beck CT. Fundamentos de pesquisa em enfermagem: avaliação de evidências para a prática da enfermagem. 7. Ed. Porto Alegre: Artmed: 2011.

9. Brasil. Instituto Nacional de Estudos e Pesquisas Educacionais Anísio Teixeira (INEP). [online]Censo da Educação Superior. Série histórica curso de enfermagem 1991 a 2009. [capturado em: 11 de outubro de 2011] Disponível em: http://portal.inep.gov.br/superiorcensosuperior. 